\title{
EFFECT OF NITRATE-N ON GROWTH AND N2 FIXATION BY Medicago sativa, L. AND Clitoria ternatea, $\mathrm{L}$. Wasfi, M.A. and Mawaheb E.M. Elnour \\ Dept. of Botany, Univ. of Khartoum, P.O.Box 321, Khartoum, Sudan
}

\begin{abstract}
Addition of nitrate significantly increased nitrogenous fractions (NO-${ }_{3}, \mathrm{~T}_{\text {.N., }}$ T., $\mathrm{S} . \mathrm{N})^{*}$, fresh and dry weights of roots and shoots in both plant species. Carbohydrates $\left(\right.$ T.S., T.,S.S ${ }^{*}$, acetylene reduction activity (A.R.A)* and nodule fresh weights were significantly decreased as compared with untreated nodulated plants. The depressive effect of nitrate on acetylene reduction activity is discussed in relation to hypotheses explaining photosynthate demand for nitrate assimilation in the nodules (assimilate deprivation), or nitrite poisoning. Present data are in favour of the assimilate deprivation hypothesis.

Keywords: Nitrates, carbohydrates, acetylene reduction activity assimilate deprivation.
\end{abstract}

\section{INTRODUCTION}

Many reports have referred to the effects of combined nitrogen on the physiology of the Rhizobium - Legume symbiosis. Eaglesham et al. (1983) reported that the effects of combined nitrogen on symbiosis, whether positive or negative, varied with the legume host and the growth stage at harvest. Many other reports emphasized the depressive effect of combined nitrogen on different growth parameters such as nodule number (Dart and Mercer, 1965), nodule mass (Summerfield et al., 1977) $\mathrm{N}_{2}$-fixing activity of nodulated roots (Gibson, 1974) and the total amount of $\mathrm{N}_{2}$ fixed (Allos and Bartholomew, 1959). The degree of depression also varied with the form of nitrogen (dart and Wildon, 1970), species (Allos and Bartholomew, 1959), cultivar (Gibson, 1974) and strain of Rhizobium (Pate and Dart, 1961). On the other hand, a few reports have established stimulative effects on different growth parameters when combined nitrogen was applied at low levels, (Ezedinma, 1964, Agboola, 1978, Huxley, 1980 and Minchin et al., 1981).

In the present work, we have investigated the effect of nitrate-N $(7 \mathrm{mM})$ on growth of nodulated Medicago sativa L. and Clitoria ternatea L. Emphasis was centered on the effects of nitrates on $\mathrm{N}_{2}$-fixation.

\section{MATERIALS AND METHODS}

\section{Plant culture:}

Seeds of Medicago sativa L. and Clitoria ternatea L. were surface sterilized in $1 \% \mathrm{NaOCl}$ for 10 minutes, then washed several times in deionised water. The seeds wee germinated in vermiculite and were watered alternately with water and $\mathrm{N}$-free nutrient solution as described by (Rigaud and Puppo, 1977). Comparable seedlings were thinned to 1 per pot, and were then separated under the following range of conditions:

${ }^{*} \mathrm{No}_{3}{ }_{3}=$ Nitrates, T.N. $=$ Total Nitrogen, T.S.N. $=$ Total Soluble Nitrogen, T.S. $=$ Total Sugars T.S.S. $=$ Total Soluble Sugars, A.R.A.= Acetylene Reduction Activity. 


\section{A- Medicago sativa L.}

a) Seedlings were inoculated with a suspension of Rhizobium meliloti (strain TAL 380 obtained from NIFTAL project, University of Hawaii, U.S.A).

b) Seedlings inoculated as above plus $3.5 \mathrm{mM}$ calcium nitrate $\left(7 \mathrm{mM} \mathrm{NO}^{-}\right)$

iii) Seedlings were inoculated with a suspension of Rhizobium meliloti (isolate SUD 120, which was locally isolated and authenticated).

iv) Seedlings inoculated as above (iii) plus $3.5 \mathrm{mM}$ calcium nitrate $(7 \mathrm{mM}$ $\mathrm{NO}_{3}^{-3}$.

\section{B- Clitoria ternatea L.}

Same protocol as above was followed except that inoculation was done by Rhizobium sp. (strain TAL 1282 obtained from NIFTAL project, University of Hawaii, U.S.A) and (isolate SUD 150) which was isolated and authenticated from locally grown plants.

For nitrate treatment, $3.5 \mathrm{mM}$ calcium nitrate $\left(7 \mathrm{mM} \mathrm{NO}^{-}\right)$was added to the root medium, one week before the termination of the experiment at the age of 6 weeks. At the stage, nodules were fully developed and active. The plants were kept in a glasshouse at mean temperatures $37^{\circ} \mathrm{C}$ day, $27^{\circ} \mathrm{C}$ night and a $12 \mathrm{~h}$ photoperiod. The experiment was set up in a randomized block design with 5 replications.

\section{Acetylene Reduction Activity (A.R.A):}

The classical acetylene reduction method was applied to intact plants (Hardy et al., 1968). Roots of nodulated plants at the age of 6 weeks wee placed in air tight flasks. A known volume of air was withdrawn from the flasks and replaced by an equal volume of acetylene so as to maintain a final $15 \% \mathrm{v} / \mathrm{v}$. Nodulated roots were incubated in this atmosphere for 30 minutes and ethylene produced was measured by gas chromatography (INFOTRONICS 2400), Kinetics were linear.

\section{Nitrate assay:}

Dried samples were ground and $100 \mathrm{mg}$ of powder were mixed with 10 $\mathrm{ml}$ distilled water for $1 \mathrm{~h}$ at $45^{\circ} \mathrm{C}$. The supernatant after 15 min centrifugation $(5000 \mathrm{~g})$ was used for nitrate determination by the salicylic method (Cataldo et al., 1975).

\section{Nitrogen fractions:}

The Total Nitrogen (T.N) was determined in the dried tissues by the conventional micro-Kjeldah 1 method as described by Pirie (1955).

The Total Soluble Nitrogen (T.S.N) was determined in water extracts of the tissues titrates using the micro - Kjeldah 1 method modified to include nitrates and nitrites as outlined by Pucher et al. (1930) and Humphries, (1956). In both cases, the plant material was digested with concentrated $\mathrm{H}_{2}$ $\mathrm{SO}_{4}$ in the presence of catalysts and the nitrogen was measured by steam distillation of ammonia from Kjeldah 1 digests.

\section{Carbohydrate extraction and analysis:}

Sugars were extracted by methanol - chloroform - water mixtures as described in Dickson (1975). The upper (lighter) soluble fraction dried and redissolved in water was used for the assay. Total Reducing Sugars (T.R.S) wee assayed by the method developed by Somogyi (1937) and described by 
Nelson (1944). Aliquot water extracts were mixed with alkaline copper reagent and read at $520 \mathrm{~nm}$ using Spectrophotometer (SPECTRONIC 20). The Total Soluble Sugars (T.S.S) were measured by the anthrone method (Halhoul and Kleinberger, 1972).

\section{RESULTS}

Data from Table (1) show the effect of nitrate nutrition at the concentration of $7 \mathrm{mM}$ on vegetative growth (dry and fresh weights of roots, shoots and nodules). Significant increases in fresh and dry weights of shoots and roots were observed as compared with untreated nodulated plants. However, this increase was accompanied by a drastic decrease in nodule fresh weight. It is evident that the two experimental plants responded more or less similarly to nitrate addition. The influence of nitrate nutrition on nitrogenous fractions, sugar content and A.R.A in Medicago sativa L. and Clitoria ternatea L. was demonstrated in Tables (2 and 3). As would be expected at this stage, applied nitrates stimulated accumulation of all nitrogen fractions assayed. On the other hand, application of nitrates resulted in significant reduction of carbohydrates fraction in shoots, roots and nodules.

Table (1): Effect of $\mathrm{Ca}\left(\mathrm{NO}_{3}\right)_{2}$ 4. $\mathrm{H}_{2} \mathrm{O}(3.5 \mathrm{mM})$ on different growth parameters of Medicago sativa L. and Clitoria ternatea $\mathrm{L}$. Each value represents the mean of 5 replicates \pm SE.

\begin{tabular}{|c|c|c|c|c|c|c|}
\hline & & & & \multirow{2}{*}{\multicolumn{2}{|c|}{ Roots }} & \\
\hline \multirow[b]{2}{*}{ Legume Host } & \multirow[b]{2}{*}{$\begin{array}{c}\text { Inoculated } \\
\text { with }\end{array}$} & \multicolumn{2}{|c|}{ Shoots } & & & \multirow{2}{*}{$\begin{array}{c}\text { Nodule } \\
\text { fresh } \\
\text { wt./plant } \\
\text { (g) }\end{array}$} \\
\hline & & $\begin{array}{l}\text { Fresh wt. } \\
\text { per plant } \\
\text { (g) }\end{array}$ & $\begin{array}{c}\text { Dry wt. per } \\
\text { plant (g) }\end{array}$ & $\begin{array}{l}\text { Fresh wt. } \\
\text { per plant } \\
\text { (g) }\end{array}$ & $\begin{array}{c}\text { Dry wt. per } \\
\text { plant (g) }\end{array}$ & \\
\hline \multirow[t]{4}{*}{ M. sativa L. } & TAL 380 & $0.9 \pm 0.02$ & $0.6 \pm 0.006$ & $1.0 \pm 0.04$ & $0.5 \pm 0.008$ & $0.30 \pm 0.04$ \\
\hline & $\begin{array}{l}\text { TAL } 380+ \\
\mathrm{NO}_{3}^{-}\end{array}$ & $1.3 \pm 0.04$ & $0.8 \pm 0.004$ & $1.6 \pm 0.08$ & $0.7 \pm 0.002$ & $0.14 \pm 0.08$ \\
\hline & SUD 120 & $1.1 \pm 0.03$ & $0.7 \pm 0.008$ & $1.2 \pm 0.03$ & $0.6 \pm 0.003$ & $0.25 \pm 0.03$ \\
\hline & $\begin{array}{l}\text { SUD } 120 \\
+\mathrm{NO}^{-}\end{array}$ & $1.5 \pm 0.04$ & $0.8 \pm 0.006$ & $1.6 \pm 0.04$ & $0.9 \pm 0.005$ & $0.15 \pm 0.04$ \\
\hline \multirow{4}{*}{ C. } & TAL 1282 & $1.1 \pm 0.01$ & & & & $0.35 \pm 0.04$ \\
\hline & $\mid \begin{array}{l}\text { TAL } 1282+ \\
\mathrm{NO}_{3}^{-}\end{array}$ & $1.5 \pm 0.02$ & $0.6 \pm 0.003$ & $1.6 \pm 0.03$ & $0.6 \pm 0.003$ & $0.20 \pm 0.08$ \\
\hline & SUD 150 & $1.2 \pm 0.03$ & $0.7 \pm 0.006$ & $1.2 \pm 0.04$ & $0.7 \pm 0.006$ & $0.25 \pm 0.03$ \\
\hline & $\begin{array}{l}\text { SUD } 150 \\
+\mathrm{NO}^{-}\end{array}$ & $1.7 \pm 0.04$ & $0.8 \pm 0.005$ & $1.6 \pm 0.03$ & $0.8 \pm 0.005$ & $0.12 \pm 0.04$ \\
\hline
\end{tabular}


Wasfi, M.A. and Mawaheb E.M. Elnour

$2-3$ 
It is important to observe the depressive effect of nitration on nodule carbohydrate content (T.S and T.S.S) and acetylene reduction on nodules (A.R.A). Plants harvested after 7 days of exposure to nitrate showed an approximate 3-4 fold decline in nodule activity relative to control plants. It is worthmentioning that, the imported Rhizobium strains (TAL 380 and TAL 1282) and the two locally isolated and authenticated isolates (SUD 120 and SUD 150) nodulated the experimental plants more or less similarly and this was verified when the plants were analysed for different components.

\section{RESULTS}

The influence of nitrates in the Rhizobium - legume symbiosis is still not well understood. The results and conclusions already obtained are very variable and in some cases contradictory (Salvagiotti et al., 2008). Our study revealed that, a close relationship was observed between nitrate - induced inhibition of $\mathrm{N}_{2}$-fixation, reduction of assimilate import to shoots and roots and lowering of nodule carbohydrate content. The interpretation of this effect of nitrate on carbon import and metabolism in the nodule remain unclear (Arrese - Igor et al., 1997). The rapid induction of the nitrate assimilation pathways in the plant may represent an important competitive sink for assimilates. This idea is supported by the reduction in the size of all the carbohydrate pools in the different organs (Tables 2 and 3). However, the specific inhibition of carbon translocation to nodules is difficult to explain by reduced sink demand, since the onset of an active nitrate assimilation in the nodule is also energy demanding. Lowering of respiratory capacities may provide another inhibitory mechanism.

An inhibition of nodule respiration was observed in nitrate treated plants Wasfi (1983). Trinchant and Rigaud (1981) demonstrated that this effect originated from impairment of bacteroid respiration and decreased affinity for respiratory substances. The increased nitrate reductase activity, the nitrite accumulation and the low nitrite reductase give support to an inhibitory role of nitrite on $\mathrm{N}_{2}$-fixation as proposed by Wasfi (1983). So, additional inhibitory mechanisms are probably encountered. Closer examination of the relationship between $A, R, A$ and carbohydrate content shows that $11-12 \%$ reduction in T.S.S of the nodules of Medicago sativa $\mathrm{L}$. nodulated with strain TAL 380, corresponded to approximately 4-fold decrease in A.R.A in nitrate treated plants. Similar values were obtained in Clitoria ternatea L.

In conclusion, the results obtained in this study support the carbohydrate deprivation hypothesis, which was forwarded to explain the depressive effect of nitrates on $\mathrm{N}_{2}$-fixation. But, the hypothesis is unable to explain the totality of inhibition and much remain to be done in this field. 


\section{REFERENCES}

Agboola, A.A. (1978). Influence of soil organic matter on cowpea's response to $\mathrm{N}$-fertilizer. Agron. J. 70: $25-28$.

Allos, H.F. and W.V. Bartholomew (1959). Replacement of symbiotic fixation by available nitrogen. Soil Sci., 87: $61-66$.

Arrese - Igor, C., F.R. Minchin; A.J. Gordon and A.K. Nath (1997). Possible causes of the physiological decline in soybean nitrogen fixation in the presence of nitrate. J. Exp. Bot. 48: $905-913$.

Cataldo, D.A., H. Haroon; L.E. Shrader and V.L. Youngs (1975). Rapid colorimetric determination of nitrate in plants by nitration of salicylic acid. Commun. Soil Sci. Plant Anal. 6: $71-80$.

Dart, R.J. and F.V. Mercer (1965). The effect of growth temperature, level of ammonium nitrate and light intensity on the growth and nodulation of cowpea (Vigna unguiculata Endl. Ex. Hassk) Aust. J. Agric. Res. 21: 45 -56 .

Dart, R.J. and D.C. Wildon (1970). Nodulation and nitrogen fixation by Vigna unguiculata and Vicia atropurpurea: The influence of nitrogen. Aust. J. Agric. Res. 21: $45-56$.

Dickson, R.E. and P.R> Larson (1975). Incorporation of photosynthate into major chemical fractions of source and sink leaves of cottonwood. Plant Physiol. 56: $185-193$.

Eaglesham, A.R.J.; S. Hassouna and R. Seegers (1983). Fertilizer-N effects on $\mathrm{N}$-fixation by cowpea and soybean. Agron. J. 75: $61-66$.

Ezedinma, F.O.C. (1964). Effects of inoculation with local isolates of cowpea Rhizobium and application of nitrate - nitrogen on the development of cowpeas, Trop. Agric. (Trinidad) 41: $243-249$.

Gibson, A.H. (1974). Consideration of the legume as a symbiotic association. In: Indian Nat. Sci. Acad. Proc. 40B: $741-767$.

Halhoul, M.N. and J. Kleinberger (1972). Differential determination of glucose and fructose and glucose - and fructose - yielding substances with anthrone. Anal. Biochem. 50: $337-343$.

Hardy, R.W.F., R.D. Holsten; E.K. Jackson and R.C. Burns (1968). The acetylene assay for $\mathrm{N}$-fixation: Laboratory and field evaluation. Plant Physiol. 43: $1185-1207$.

Humphries, E.C. (1956). Modern methods of plant analysis. Paech, K. and Tracey, M.V (eds) Springer Verlag, Berlin. 1: 468 - 502.

Huxley, P.A. (1980). Nitrogen nutrition of cowpea (Vigna unguiculata). IVUptake and distribution of a single dose of early applied nitrogen. Trop. Agric. (Trinidad) 57: $193-202$.

Lawrie, A.C. and C.T. Wheeler (1975). Nitrogen fixation in the root nodules of Vicia faba $\mathrm{L}$. in relation to the assimilation of carbon. I. Plant growth and metabolism of photosynthetic assimilates, New Phytol. 74: 429 436. 
Minchin, F.R., R.J. Summerfield and M.C.P. Neves (1981). Nitrogen nutrition of cowpeas (Vigna unguiculata): effects of timing of inorganic nitrogen application on nodulation, plant growth and seed yield. Trop. Agric. (Trinidad) 85: 7 - 12 .

Nelson, N.J. (1944). A photometric adaptation of the Somogyi method for the determination of glucose. J. Biol. Chem. 153: $375-380$.

Pate, J.S. and P.J. Dart (1961). Nodulation studies in legumes. IV. The influence of inoculum strain and time of application of ammonium nitrate on symbiotic response. Plant Soil. 15: $329-346$.

Pirie, N.W. (1955). Modern methods of plant analysis. Paech, K. and Tracey, M.V. (eds). Springer Verlag, Berlin. IV, $23-41$.

Pucher, G.W., C.S. Leavenworth and H.B. Vickery (1930). Determination of total nitrogen of plant extracts in presence of nitrates. Ind. And Eng. Chem. Anal. Ed. 2: $191-193$.

Rigaud, J. and A. Puppo (1977). Effect of nitrite upon leghemoglobin and interaction with nitrogen fixation. Biochem. Biophys. 497: $702-706$.

Salvagiotti, F., K.G. Cassman; J.E. Specht; D.T. Walters; A. Weiss and A. Dobermann (2008). Nitrogen uptake, fixation and response to fertilizer nitrogen in soybeans: A review. Field Crops Research. 108: 1 - 13.

Somogyi, M. (1937). A reagent for the copper - iodometric determination of very small amounts of sugars. J. Biol. Chem. 177: $771-775$.

Summerfield, R.J., P.J. Dart; P.A. Huxley; A.R.J. Eaglesham; F.R. Minchin and J.M. Day (1977). Nitrogen nutrition of cowpea (Vigna unguiculata). I. Effects of applied nitrogen and symbiotic nitrogen fixation on growth and seed yield. Exp. Agric. 13: $129-142$.

Trinchant, J.C. and J. Rigaud (1981). Nitrite inhibition of nitrogen from soybean bacteroids. Arch. Microbiol. 124: 49 - 54.

Wasti, M.A. (1983). Analyse de l'inhibition de la fixation symbiotique d'azote des legumineuses lors d'un apport de nitrate. These de 3eme cycle. L'unversite de paris - sud. France.

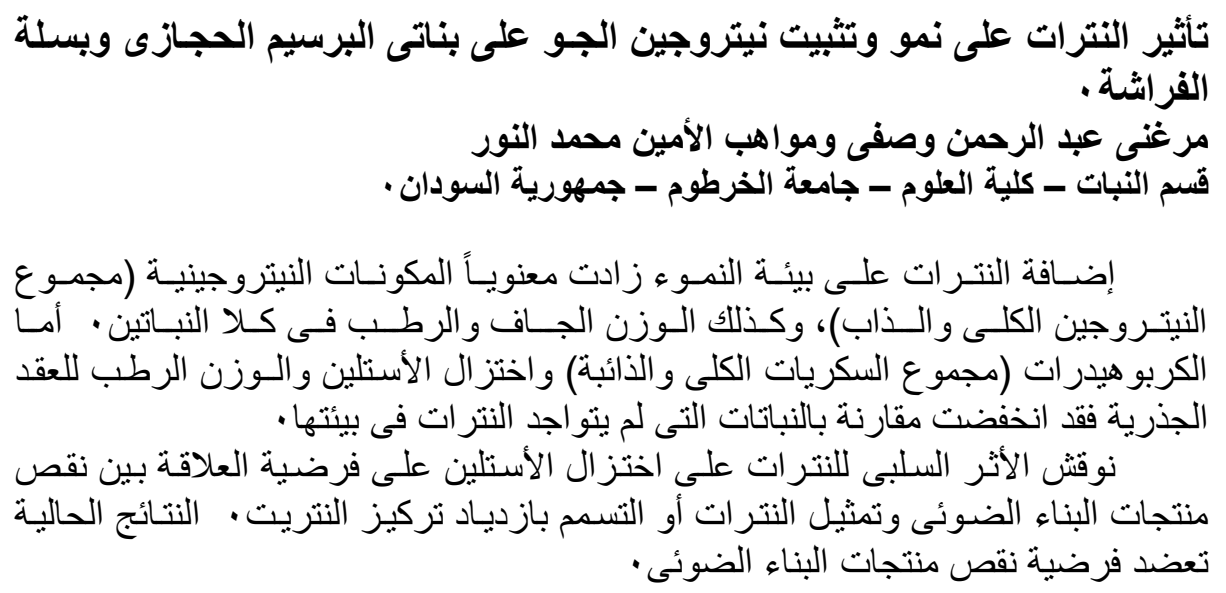


Table (2): Effect of $\mathrm{Ca}\left(\mathrm{NO}_{3}\right)_{2} 4 . \mathrm{H}_{2} \mathrm{O}(3.5 \mathrm{mM})$ on different nitrogenous fractions, sugar content and acetylene reduction activity of Medicago sativa L. Each value represents the mean of 5 replicates \pm SE.

\begin{tabular}{|c|c|c|c|c|c|c|c|}
\hline $\begin{array}{l}\text { Plant } \\
\text { organ }\end{array}$ & Inoculated with & $\begin{array}{l}\%^{*} \\
\text { T.N }\end{array}$ & $\begin{array}{c}\%^{\star \star} \\
\text { T.S.N }\end{array}$ & \begin{tabular}{c|}
$\%$ \\
$\mathrm{NO}_{3}$ \\
\end{tabular} & $\begin{array}{c}\text { T.S.S } \dot{S}^{\star \star \star} \\
(\mathbf{m g})\end{array}$ & $\begin{array}{c}\text { T.R.S } \\
(\mathbf{m g})\end{array}$ & $\begin{array}{c}\text { A.R.A }{ }^{\star \star \star \star \star \star} \\
\mu \text { moles/h/gm F. Wt. nodule }\end{array}$ \\
\hline \multirow[t]{4}{*}{ Shoot } & TAL 380 & $3.2 \pm 0.08$ & $2.1 \pm 0.08$ & $0.40 \pm 0.06$ & $1.8 \pm 0.07$ & $0.70 \pm 0.07$ & - \\
\hline & $\mathrm{TAL} 380+\mathrm{NO}_{3}^{-}$ & $3.6 \pm 0.04$ & $2.4 \pm 0.07$ & $0.60 \pm 0.04$ & $1.6 \pm 0.04$ & $0.50 \pm 0.04$ & - \\
\hline & SUD 120 & $3.0 \pm 0.04$ & $1.9 \pm 0.07$ & $0.32 \pm 0.06$ & $1.9 \pm 0.10$ & $0.80 \pm 0.01$ & - \\
\hline & SUD $120+\mathrm{NO}_{3}^{-}$ & $3.5 \pm 0.04$ & $2.3 \pm 0.06$ & $0.50 \pm 0.05$ & $1.6 \pm 0.08$ & $0.70 \pm 0.04$ & - \\
\hline \multirow[t]{4}{*}{ Root } & TAL 380 & $4.5 \pm 0.03$ & $3.1 \pm 0.05$ & $0.78 \pm 0.01$ & $1.5 \pm 0.08$ & $0.64 \pm 0.01$ & - \\
\hline & TAL $380+\mathrm{NO}_{3}^{-}$ & $6.2 \pm 0.02$ & $3.8 \pm 0.03$ & $0.95 \pm 0.04$ & $1.1 \pm 0.03$ & $0.52 \pm 0.04$ & - \\
\hline & SUD 120 & $4.1 \pm 0.05$ & $2.6 \pm 0.10$ & $0.75 \pm 0.01$ & $1.2 \pm 0.04$ & $0.65 \pm 0.01$ & - \\
\hline & SUD $120+\mathrm{NO}_{3}$ & $6.0 \pm 0.04$ & $3.5 \pm 0.10$ & $0.92 \pm 0.02$ & $5.9 \pm 0.05$ & $0.50 \pm 0.01$ & - \\
\hline \multirow[t]{4}{*}{ Nodule } & TAL 380 & - & - & - & $2.0 \pm 0.05$ & $0.90 \pm 0.03$ & $360 \pm 3.70$ \\
\hline & $\mathrm{TAL} 380+\mathrm{NO}_{3}^{-}$ & - & - & - & $1.8 \pm 0.02$ & $0.70 \pm 0.04$ & $80 \pm 1.80$ \\
\hline & SUD 120 & - & - & - & $1.8 \pm 0.06$ & $0.82 \pm 0.04$ & $369 \pm 0.01$ \\
\hline & SUD $120+\mathrm{NO}_{3}$ & - & - & - & $1.6 \pm 0.04$ & $0.72 \pm 0.03$ & $922 \pm 0.04$ \\
\hline
\end{tabular}

* Total nitrogen content.

**** Total reducing sugars.
** Total soluble nitrogen

***** Acetylene reduction activity.
${ }^{\star \star \star}$ Total soluble sugars. 
Table (3): Effect of $\mathrm{Ca}\left(\mathrm{NO}_{3}\right)_{2} 4 . \mathrm{H}_{2} \mathrm{O}(3.5 \mathrm{mM})$ on nitrogenous fractions, sugar content and acetylene reduction activity of Clitoria ternatea L. Each value represents the mean of 5 replicates \pm SE.

\begin{tabular}{|c|c|c|c|c|c|c|c|}
\hline $\begin{array}{l}\text { Plant } \\
\text { organ }\end{array}$ & Inoculated with & $\begin{array}{c}\% \\
\text { T.N }\end{array}$ & $\begin{array}{c}\% \\
\text { T.S.N }\end{array}$ & $\begin{array}{c}\% \\
\mathrm{NO}_{3} \\
\end{array}$ & $\begin{array}{l}\text { T.S.S } \\
\text { (mg) }\end{array}$ & $\begin{array}{l}\text { T.R.S } \\
\text { (mg) }\end{array}$ & $\begin{array}{c}\text { A.R.A } \\
\mu \text { moles/h/gm F. Wt. nodule }\end{array}$ \\
\hline \multirow[t]{4}{*}{ Shoot } & TAL 1282 & $3.5 \pm 0.05$ & $2.0 \pm 0.04$ & $0.40 \pm 0.02$ & $1.5 \pm 0.02$ & $0.5 \pm 0.03$ & - \\
\hline & TAL 1282+NO- 3 & $4.0 \pm 0.03$ & $2.2 \pm 0.04$ & $0.50 \pm 0.04$ & $1.3 \pm 0.08$ & $0.4 \pm 0.02$ & - \\
\hline & SUD 150 & $3.8 \pm 0.05$ & $2.1 \pm 0.02$ & $0.45 \pm 0.04$ & $1.4 \pm 0.03$ & $0.6 \pm 0.03$ & - \\
\hline & SUD $150+\mathrm{NO}_{3}^{-}$ & $4.2 \pm 0.07$ & $2.3 \pm 0.05$ & $0.60 \pm 0.05$ & $1.2 \pm 0.06$ & $0.4 \pm 0.04$ & - \\
\hline \multirow[t]{4}{*}{ Root } & TAL 1282 & $5.0 \pm 0.05$ & $3.8 \pm 0.07$ & $0.90 \pm 0.006$ & $1.2 \pm 0.04$ & $0.72 \pm 0.005$ & - \\
\hline & $\mathrm{TAL}_{1282+\mathrm{NO}_{3}}{ }_{3}$ & $6.4 \pm 0.07$ & $4.1 \pm 0.08$ & $0.90 \pm 0.02$ & $1.0 \pm 0.10$ & $0.56 \pm 0.01$ & - \\
\hline & SUD 150 & $4.9 \pm 0.06$ & $3.2 \pm 0.04$ & $0.85 \pm 0.01$ & $1.0 \pm 0.10$ & $0.45 \pm 0.006$ & - \\
\hline & SUD $150+\mathrm{NO}_{3}$ & $5.8 \pm 0.06$ & $3.7 \pm 0.05$ & $0.91 \pm 0.01$ & $0.89 \pm 0.01$ & $0.39+0.005$ & - \\
\hline \multirow[t]{4}{*}{ Nodule } & TAL 1282 & - & - & & $1.8 \pm 0.05$ & $0.69 \pm 0.04$ & $427 \pm 5.2$ \\
\hline & $\mathrm{TAL} 1282+\mathrm{NO}_{3}^{-}$ & - & - & - & $1.5 \pm 0.04$ & $0.53 \pm 0.02$ & $108 \pm 4.1$ \\
\hline & SUD 150 & - & - & - & $1.6 \pm 0.03$ & $0.50 \pm 0.02$ & $488 \pm 5.1$ \\
\hline & SUD $150+\mathrm{NO}_{3}^{-3}$ & - & - & - & $1.3+0.05$ & $0.90+0.04$ & $112 \pm 3.9$ \\
\hline
\end{tabular}

